\title{
Reviewing the theory and practice of occupational therapy in mental health rehabilitation
}

\author{
Geoff Waghorn, ${ }^{1}$ Chris Lloyd ${ }^{1}$ and Alexis Clune ${ }^{2}$
}

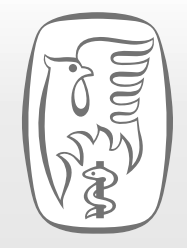

Key words:

Schizophrenia, vocational rehabilitation, employment, occupational therapy.

${ }^{1}$ Queensland Centre for Mental Health Research, Sumner Park BC, Queensland, Australia.

2 University of Queensland, St Lucia, Queensland, Australia.

Corresponding author: Dr Chris Lloyd, Queensland Centre for Mental Health Research, Locked Bag 500, Sumner Park BC, Queensland, Australia 4074.

Email: Iloyd@onthenet.com.au

Reference: Waghorn G, Lloyd C, Clune A (2009) Reviewing the theory and practice of occupational therapy in mental health rehabilitation. British Journal of Occupational Therapy, 72(7), 314-323.

(c) The College of Occupational Therapists Ltd. Submitted: 18 September 2008. Accepted: 16 March 2009
The delineation of evidence-based practices in supported employment for people with schizophrenia now represents a paradigm shift in the theory and practice of mental health rehabilitation. The principles and methods of traditional vocational rehabilitation and traditional mental health rehabilitation are giving way to evidence-based practices in supported employment, which are consistently proving two to three times more effective at producing competitive employment outcomes.

These practices include close coordination with optimal forms of mental health treatment and care and highly individualised forms of intensive supported employment. There is a focus on the vocational services being provided, whereas the traditional and currently prevailing approach follows a more gradual and stepwise process with less of an individual focus, and where individual characteristics are considered important predictors of vocational rehabilitation success.

This paradigm shift now challenges occupational therapists working in mental health rehabilitation to revise their theory and practice critically in order to support the implementation of evidence-based practices in supported employment for people with schizophrenia and related psychotic disorders. This article discusses how occupational therapists can adapt to this paradigm shift and revitalise their theory and practice in mental health rehabilitation.

\section{Introduction}

Occupations are the everyday meaningful activities that people engage in related to work, leisure and self-care, which are central components of occupational therapy. With the move to community-based care, occupational therapists have taken on a range of different roles, and many have been involved in the vocational rehabilitation of people with mental health problems. Davis and Rinaldi (2004) discussed how a mental health trust actively promoted vocational rehabilitation through implementing evidence-based principles within the clinical teams. They reported how the trust acknowledged the unique contribution of occupational therapy, in partnership with vocational services, to enable service users to access competitive employment, mainstream education and voluntary work. They suggested that occupational therapists explore the more complex roles, tasks and meaningful activities that can enhance the quality of an individual's life. Robdale (2004) argued that the occupational therapy profession needs to grasp this opportunity to reinvolve itself in an area that should be at the core of its practice. Porteous and Waghorn (2007) showed how occupational therapists in New Zealand have led the implementation, delivery and evaluation of evidence-based supported employment in multidisciplinary mental health teams.

Promoting employment and vocational opportunities are key features of present Government strategies to improve social inclusion, social 
participation and quality of life among people with disabilities and health conditions (Office of the Deputy Prime Minister 2004, Department of Health 2006). People with mental health problems, who are among the most disadvantaged groups in the community, have particularly low labour force participation and low employment rates compared with people with other categories of disability and compared with the healthy working age population (Sainsbury Centre for Mental Health 2007). Evidence-based practices in supported employment (Bond 2004), also known as individual placement and support (IPS), have set standards for more efficient forms of vocational rehabilitation.

Reviewers (Velligan and Gonzalez 2007, Bond et al 2008) note that even these evidence-based practices have much room for improvement in terms of the proportion of service users that obtain competitive employment, the time to the first job and accumulated time in employment. A greater efficiency of evidence-based supported employment programmes is needed to make competitive employment a reality for all who request this assistance. This article examines the evidence for the effectiveness of supported employment and explores how occupational therapists and other allied health professionals can be involved in the implementation of evidence-based practices for people receiving public-funded mental health care.

\section{Evidence-based supported employment}

Over the last 20 years, supported employment has been the primary means of assisting people with more severe mental health problems to attain competitive employment (Drake and Bond 2008). According to Bond (2004), the term 'supported employment' can refer to either a type of employment status or to a type of employment programme. For people with severe mental health problems, the most comprehensively described type of supported employment programme is the IPS approach (Becker and Drake 1993). The IPS model is also known as evidence-based supported employment (Rinaldi et al 2008).

High quality research over this time has identified seven principles in the provision of vocational services to people with severe mental health problems (Bond 2004). The research evidence now consists of 16 published randomised controlled trials conducted in Europe, the United States, Canada, Hong Kong and Australia (Bond et al 2008), and six day-treatment conversion studies conducted in the United States (Becker et al 2001a). The core principles identified are as follows: (1) zero exclusion where eligibility is based on service user choice; (2) supported employment is integrated with treatment; (3) the goal is always competitive employment; (4) the aim is to commence job searching and employment as soon as possible; (5) all aspects of the programme are highly individualised; (6) follow-on supports are continuous; and (7) personalised benefits counselling is provided.
The first column of Table 1 shows how these principles are operationalised in practice.

Recovery is an important concept, which is gaining momentum in mental health service delivery (Department of Health 2001). The College of Occupational Therapists (2006) stated that occupational therapists will value recovery and will work within a socially inclusive framework to achieve goals that make a difference to people's lives. Work and employment are the primary means by which people connect with their communities and build their lives (Shepherd et al 2008). It has been recognised that vocational services can be involved much earlier in the person's recovery (Munro and Edward 2008), when closely coordinated with optimal mental health treatment and care. One of the evidence-based principles in supported employment recognises the need to coordinate closely mental health treatment and care with employment assistance (Bond et al 2001, Drake and Bond 2008). This is because the treatment plan may need to be varied to optimise the person's work performance. By coordinating optimal treatment and care with highly individualised employment services, the expertise of treatment professionals and the expertise of employment specialists can converge with information provided by the service user in order to help solve specific illness-related work performance problems (Department of Health 2006, King et al 2006).

High-fidelity evidence-based supported employment programmes outperform traditional approaches to vocational rehabilitation in terms of (1) proportions of service users who attain competitive employment (62\% vs $25 \%$ ); (2) average hours worked (66\% vs 14\% worked more than 20 hours per week); (3) days to first job (144.5 vs 214 days); and (4) weeks worked at the longest job (22 vs 16 weeks). However, there are as yet no differences in accumulated employment (24.5 vs 25.0 weeks), as found in a recent review of 11 high-fidelity randomised controlled trials (Bond et al 2008). Despite these favourable results overall, major challenges remain, namely the time taken to commence the first job, the job duration and the accumulated time in employment.

There are also outstanding problems with respect to engaging all who could benefit from evidence-based supported employment services. Receiving disability payments and fringe benefits can act as a disincentive to participation and, hence, to successful vocational rehabilitation outcomes (Cook 2006). Rosenheck et al (2006), in a study of 1400 people with schizophrenia, found a negative association between disability payments and participation in competitive employment. People in receipt of a disability pension often fear losing their income support payments and their fringe benefits (Killackey et al 2006). However, the lost income support benefits may actually be of less monetary value than the potential income gain from competitive employment. To counter perceived disincentives, employment service providers can identify these for each individual by calculating the precise financial implications of commencing work. This 
Table 1. Characteristics of traditional vocational rehabilitation compared with evidence-based supported employment

\begin{tabular}{|c|c|c|}
\hline Service characteristic & Traditional vocational rehabilitation & Evidence-based supported employment \\
\hline $\begin{array}{l}\text { 1. Model definition and } \\
\text { evidence base }\end{array}$ & $\begin{array}{l}\text { Not a clearly defined model based on evidence, but } \\
\text { based on a history of eclectic practices. No fidelity scale } \\
\text { is available. Models cited include Choose-get-keep, }\end{array}$ & $\begin{array}{l}\text { Model is clearly defined according to a body of agreed } \\
\text { evidence. }{ }^{1} \text { Seven practice principles have been identified, } \\
\text { and a fidelity scale is now available. }\end{array}$ \\
\hline
\end{tabular}

\section{Expected outcomes}

3. Caseload size

4. Employment specialist role

5. Employment specialist performs all aspects of the role

6. Integration of vocational rehabilitation with mental health treatment

7. Employment specialist is part of a vocational team

8. Minimal exclusion criteria

9. Ongoing work-based assessment

10. Rapid job search

11. Individualised job search

12. Diversity of jobs developed

13. Permanence of jobs developed

14. Jobs as transitions management.

Evidence from 11 randomised controlled trials ${ }^{1}$ show that, on average, $25 \%$ attain competitive employment. Client characteristics are considered to predict employment outcomes.

Caseload size may vary from 20-60 clients (Australia) to 150 clients per worker (United States).

Employment specialists provide only vocational services.

Employment staff may specialise as intake assessors, job search specialists, maintenance support and work performance specialists.

Employment services are usually segregated from health care services.

The employment specialist is part of a vocational unit, meeting at least once per week as a group.

The service targets people with less severe disorders, such as anxiety and depression, as well as people with severe mental illness. Work readiness assessments are used to assess the client at entry. Clients considered unlikely to benefit are excluded.

Most assessment occurs before the person commences a job.

No specific focus on commencing job searching as soon as possible. An indefinite assessment period is permitted in which services other than vocational services are provided.

Programmes are individualised but may contain mandatory elements, such as getting ready for work groups, unassisted job searching and job-clubs.

No specific focus on job diversity, although most practitioners try to avoid multiple placements to the same workplace.

Temporary jobs, unpaid work experience and voluntary positions are more likely to be used.

No explicit focus on jobs as job tryouts. Substantial time is devoted to career counselling. Clients are less likely to be assisted to change jobs.
Evidence from 11 randomised controlled trials of high-fidelity services ${ }^{1}$ show that $62 \%$, on average, attain competitive employment. Service characteristics are considered to predict employment outcomes best.

Caseload size is capped at 25 active clients to maintain capacity to provide intensive services.

Employment specialists provide only vocational services and not case management services to mental health clients.

Each employment specialist carries out all phases of the vocational service, including engagement, job commencement, work performance assessment and maintenance support.

Employment specialists are part of a mental health team with shared clients and shared decision making. They attend regular treatment team meetings and have frequent contact with treatment team members.

The employment specialist is part of a vocational unit, meeting at least once per week as a group.

The service targets people with severe mental illness. Client choice is the main entry criterion. Clients with severe mental illness are not excluded on the basis of work-readiness assessments or comorbid disorders.

Vocational assessment begins once a person commences a job. The aim is to improve knowledge, skills and attitudes over time to reach the performance expectations of employers.

Every effort is made to complete all preliminary requirements and identify candidate job tryouts so that employers can be approached about competitive jobs within 4 weeks. Other services can be provided in parallel with job-searching assistance.

All assistance is highly individualised. No mandatory programme elements. Clients can choose both the type of job and the type of assistance to be provided.

Employment specialists try to follow individual preferences and try not to commence employment of more than one person in the same setting.

Only competitive jobs are sought. Temporary jobs, jobs reserved for people with disabilities, voluntary work or wage subsidies are usually avoided.

Clients are encouraged to see a job as a career learning experience, and simply to choose a few jobs they are willing to learn. Clients are assisted to change jobs when needed. 
Table 1 (continued)

\begin{tabular}{lll}
\hline Service characteristic & \multicolumn{1}{c}{ Traditional vocational rehabilitation } & \multicolumn{1}{c}{ Evidence-based supported employment } \\
\hline 15. Post-employment support & $\begin{array}{l}\text { Post-employment support is usually time limited to } \\
\text { when employment is considered stable. Support may }\end{array}$ & $\begin{array}{l}\text { Post-employment support is made available to both the } \\
\text { employer and the client on a time-unlimited basis. Contact is } \\
\text { not be routinely offered to employers. }\end{array}$ \\
& $\begin{array}{l}\text { maintained so that more intensive support can be provided } \\
\text { when needed. }\end{array}$
\end{tabular}

16. Community-based services Most services are office based and can involve giving clients tasks to accomplish without assistance. 17. Assertive engagement
and outreach.

18. Financial planning

19. Help to manage sensitive personal information

20. Supported education
No specific focus on assertive outreach to re-engage clients. Case closure may follow from two or three failed contact attempts.

Financial planning may be provided in response to specific issues raised by the client.

Help with this is provided when requested, or when clients refuse disclosure, but there is not usually a formal plan to manage sensitive personal information consistently.

Not usually provided unless the funding agency permits this form of assistance.
Most vocational services are provided in natural community settings. The employment specialist aims to be out of the office with clients $70 \%$ of the time.

Clients are not closed if they simply stop attending. Outreach by telephone, mail and home visit on several occasions are used to locate clients actively and help them to re-engage in the programme.

Financial planning is routinely provided at commencement to increase motivation by identifying all the financial implications of employment.

Help with this is provided when requested or when clients refuse disclosure, but there is not usually a formal plan to manage sensitive personal information consistently.

Not routinely provided except with youth-oriented services.

Notes: 1. The evidence base is presented in Bond (2004) and Bond et al (2008). 2. Items 3-17 reflect the fidelity items in the scale used to assess the quality of implementation of evidence-based practices.

can be achieved by preparing a detailed budget for the first 4 weeks of employment and the implications for income support and non-monetary welfare benefits.

\section{Traditional mental health vocational rehabilitation}

Despite the demonstrated effectiveness of supported employment, vocational and mental health services continue to be dominated by obsolete models, poor financing and staff resistance to change (Drake and Bond 2008). Traditional practices in mental health vocational rehabilitation are sometimes described as a 'train then place' approach; this can be clearly differentiated from evidence-based supported employment, which is more like a 'place then train' method.

In traditional practices, it is assumed that people with mental health problems require a long period of preparation before entering into competitive employment. This type of thinking leads to extensive prevocational training, which may include sheltered workshops, transitional employment, work crews, skills training and other preparatory activities designed to prepare people for the open labour market (Crowther et al 2001). On the other hand, supported employment places service users directly in the competitive employment of their choice, without extended preparation, but provides an extensive range of post-employment support based on individual needs (Crowther et al 2001). In a systematic review, Crowther et al (2001) found that supported employment was more effective than prevocational training at helping people with severe mental health problems to obtain competitive employment.

Table 1 shows a type of traditional vocational rehabilitation service. The characteristics of this paradigm are eclectic and have historical origins, rather than being influenced by a current evidence base. The theoretical principles are drawn from a variety of sources: traditions in general medical rehabilitation, practices in disability support services, assertive and strengths-based case management, and other established principles in psychosocial rehabilitation.

Traditional mental health vocational rehabilitation often involves a gradual and stepwise approach, with little urgency around commencing competitive employment. Consequently, traditional approaches can take on average 7 months to the first job, compared with 4.7 months in evidence-based approaches (Bond et al 2008). In addition, vocational services are typically segregated from treatment and care services, although the rehabilitation staff may attempt communication regularly with mental health treatment and care providers. Traditional approaches value rehabilitation professionals' assessments of individual characteristics as valid and necessary to determine service user eligibility; determine appropriate service user programme goals; identify programme elements; 
and predict service user outcomes. However, evidence-based supported employment has a zero exclusion and provides a service if a service user has a desire to return to work, irrespective of other assessments.

\section{Labour force exclusion as a rationale and benchmark for change}

High levels of labour force exclusion at a population level among people with schizophrenia provide a strong rationale for the provision of vocational rehabilitation to this group as well as to people with other categories of psychiatric disorders. In 2003, among Australian adults with schizophrenia compared with healthy adults, $73.5 \%$ vs $19.1 \%$ were not participating in the labour force, $10.6 \%$ vs $4.0 \%$ were looking for work actively, and $15.9 \%$ vs $76.9 \%$ were employed either full time or part time (Waghorn et al 2009). Hence, people with schizophrenia may need more intensive and continuous forms of employment assistance than they currently receive.

The extent of labour force exclusion indicates that current systems of vocational rehabilitation are not meeting the needs of this group at a population level and provides a benchmark for change as evidence-based practices are introduced. If evidence-based supported employment continues to be more effective than traditional rehabilitation at a population level, then there should be a reduction in non-participation in the labour force and a corresponding increase in the proportions employed over time.

\section{Individual characteristics as predictors of assistance needs}

There are many predictors of employment outcomes among people with psychotic disorders. These have been reviewed by Tsang et al (2002) and studied at a population level (for example, Waghorn et al 2004, Waghorn and Chant 2005). The strongest of these are severity of illness category, extent of employment restrictions, course pattern of illness (Waghorn et al 2003), work history and work skills (Tsang et al 2002, Bond and Drake 2008), premorbid work adjustment (Tsang et al 2002), educational attainment (Waghorn et al 2003, 2005) and labour market conditions (Burns et al 2007). Positive labour market conditions can be considered a mediating effect, and negative conditions a moderating effect, when there is a surplus of workers compared with job vacancies (Waghorn et al 2009).

Although numerous individual characteristics are associated with employment outcomes at a population level, evidence-based practices in supported employment show that the provision of an intensive one-to-one service can counter all forms of disadvantage at the individual level (Rinaldi and Perkins 2007). This means that a focus on individual characteristics is relevant to identifying specific assistance needs and the cost of the assistance required; however, it is not relevant to determining programme eligibility or access to assistance, if the individual wants the assistance and his or her needs warrant the intensity of assistance provided by evidencebased supported employment.

Assessment of the service user begins at programme entry, with the service typically exercising a right of refusal to provide services if the service user is deemed too costly or too difficult to assist. Service users with comorbid substance misuse, a forensic history or antisocial behaviour may be denied services on the basis of not being considered likely to succeed. The evidence indicates that if a service user is stating clearly that he or she wants assistance to obtain employment, that service can be provided successfully and the likelihood of success depends on the type of assistance provided. This does not mean that places in the most intensive and costly services are unrestricted; rather, it means that a triage system is valid to ensure that people with psychotic disorders and complex comorbid disorders, who are likely to need the most intensive assistance, obtain access to that assistance.

\section{Reviewing the role of occupational therapists in mental health rehabilitation}

Evidence-based approaches to supported employment are necessary but not sufficient to attain employment outcomes for all people with severe mental illness. Yet, most if not all occupational therapists currently practising in mental health will have been trained in traditional vocational rehabilitation and may have little knowledge of these evidence-based practices. Table 1 shows the specific practices required when implementing evidence-based supported employment. Table 2 shows how occupational therapists can participate in evidence-based practices in supported employment.

An essential feature of evidence-based supported employment is the dedicated employment specialist, who has primary responsibility for implementing the intervention and who operates from within the community mental health team (Rinaldi et al 2008). Employment specialists tend not to be mental health professionals, but usually have skills and experience in vocational rehabilitation or relevant business or industry experience. They work directly with the service user to address individual vocational needs and help to ensure that vocational goals are given a high priority within the mental health care plan (Rinaldi et al 2008). The report Vocational services for people with severe mental health problems: commissioning guidance describes a leadership role to coordinate these services within mental health teams (Department of Health 2006). Although this role could be filled by any allied health professional working in a community mental health team, it could particularly suit occupational therapists with an interest in vocational rehabilitation. 
Table 2. Making the paradigm shift: new task and role opportunities for occupational therapists

$\begin{aligned} & \text { Implications from the evidence-based } \\ & \text { practices in supported employment }\end{aligned}$
$\begin{aligned} & \text { 1. Review the need for systems change; } \\ & \text { plan, implement and maintain a suite of } \\ & \text { evidence-based practices in psychosocial } \\ & \text { rehabilitation }\end{aligned}$
$\begin{aligned} & \text { 1.1. Study the evidence for evidence-based practices and become an advocate for system change. } \\ & \text { 1.2. Disengage from providing non-evidence-based forms of psychosocial rehabilitation. } \\ & \text { primary psychosocial rehabilitation strategy. } \\ & \text { 1.4. Plan and implement other evidence-based practices, such as family psychoeducation and assertive } \\ & \text { community treatment models of case management. } \\ & \text { 1.5. Design training for other clinical team members in each evidence-based practice. } \\ & \text { 1.6. Evaluate programme effectiveness. } \\ & \text { 1.7. Conduct high quality research using the new programmes. }\end{aligned}$

2. Planning new services

3. Implementing new services

\author{
4. Maintaining fidelity with evidence-based \\ practices
}

5. Increasing the efficiency of the new service

6. Evaluating the new service
2.1. Train occupational therapists in the new role as employment specialist.

2.2. Use such a trained occupational therapist to lead a small team of employment and education specialists.

2.3. Include high quality research in the implementation plan.

2.4. Use average outcomes previously reported to set performance expectations for the new service.

2.5. Negotiate the resources and funding structures that will ensure the programme is sustainable.

3.1. Become a champion advocate for the new evidence-based practices at the implementation site.

3.2. Establish and lead a steering group of key decision makers to oversee the new service in the first year.

3.3. Encourage other clinical team members to make referrals to the new services.

3.4. Encourage others to phase out the use of non-evidence-based practices in psychosocial rehabilitation.

4.1. Become involved in fidelity measurement as a routine management practice.

4.2. Encourage managers and staff to solve problems by making decisions that increase, and not decrease, fidelity with evidence-based practices.

5.1. Plan and implement add-on programmes to enhance competitive employment outcomes further.

5.2. Study programme problems, such as reasons for job loss, to find ways to improve programme outcomes.

5.3. Assist clients to use the employment and education experiences to increase their social inclusion in the wider community.

6.3. Implement evaluation and research designs that can be reported in peer-reviewed publications.

6.4. Use these reports to promote system change and plan even more effective services.

6.5. Use the knowledge gained to assist in workforce development by helping to train and supervise new employment and education specialists.
There are other ways in which mental health team members can facilitate competitive employment outcomes. They can help to focus their clinical perspective on the individual problems encountered in every stage of vocational rehabilitation and offer advice and guidance on vocational challenges to other team members. They can also provide brief interventions that help service users to clarify and achieve their vocational goals, while working closely with the employment specialist and through collaborations with other local employment service providers (Department of Health 2006).

Occupational therapists can also advocate for system change, which in turn requires a detailed knowledge of the evidence base and the competitive employment outcomes that can be expected. System change is a difficult science, particularly in mental health, but there are many ways in which allied health professionals can facilitate system change in their current practices. For instance, in New Zealand (Porteous and Waghorn 2007), the occupational therapists changed their role within the youth mental health service from that of a traditional rehabilitation adviser to an employment specialist with a full caseload, consisting of referrals from other clinical team members. At several sites in Australia (Waghorn et al 2007a) the occupational therapist is taking a different approach, by leading the change involved in establishing a co-located employment specialist, employed by an external disability employment agency, within the mental health team.

There are many other ways in which occupational therapists can facilitate the shift to evidence-based practices. New services need to be planned and implemented, and non-evidence-based practices may need to be phased out. In addition, maintaining the quality and fidelity of the evidence-based service over time is critical. For example, the Supported Employment Fidelity Scale - Implementation Questions (Becker et al 2001b) has proven useful in assessing the quality of the implementation of the supported employment programme. This measure consists of 15 core questions covering 'caseload size', 'the integration of 
vocational staff', 'individualised job search' and 'followalong supports'. Total scores indicate the relative strength of implementation fidelity. There is also an increased need for individual assessment and measurement when conducting evidence-based supported employment, but not before a person starts a job. Once a job has commenced, there are opportunities to trial a range of add-on programmes, which show promise in terms of improving work performance and job retention. Some of these programmes are too intensive, time consuming or experimental to be conducted by employment specialists and are best conducted by interested allied health professionals. Some of the most promising add-on programmes are described as follows.

\section{Cognitive training}

Cognitive impairment can be challenging in all forms of vocational rehabilitation (Gold et al 2002, Honkonen et al 2007). People with schizophrenia may be unaware of the assistance available or unable to access the most suitable services to help them to gain employment. A person with schizophrenia can find the process of going to various agencies for income support, medical assessments and subsequent referral to suitable services too stressful or overwhelming and may either not engage or may withdraw from the vocational rehabilitation process. However, once participating, cognitive remediation has been found to enhance positive outcomes in supported employment. In a randomised control trial examining cognitive remediation combined with supported employment, McGurk et al (2007) found that when the two interventions were combined, those with severe mental health problems were more likely to be employed, worked more hours and earned more pay.

A variation on cognitive remediation is problem-solving training. This can be either task focused or socially focused, and is best conducted post-employment. Stålberg et al (2008) found severe deficits in interpersonal problem solving in people with schizophrenia. The skills required include: attempting to identify a problem when it occurs; defining a problem; understanding the problem; setting goals related to the problem; generating alternative solutions; evaluating and choosing the best alternative; implementing the chosen alternative; and evaluating the efficacy of the problem-solving effort (Malouff et al 2007). This approach is promising as a post-employment intervention where the employment context can be used to identify potential problems, for which a range of solutions can be devised and rehearsed.

\section{Work-related social skills}

Training in social skills has a long history as a standard intervention in traditional mental health rehabilitation (Tsang and Pearson 2000, Tsang 2001, Penn et al 2007). However, the social skills commonly taught in prevocational settings do not generalise to specific employment contexts (Kopelowicz et al 2006). Supported employment participants often experience difficulties in work-related social situations, such as getting along with co-workers, interacting with customers and responding to feedback and criticism from supervisors (Mueser et al 2005).

Cheung and Tsang (2005) discovered that social skills are most effectively taught after a person has a job, when perceptions of relevance are high and the context is clearly defined. For instance, post-employment social skills training for retail sales assistants has been found to improve greatly the job retention of retail sales workers with schizophrenia. Cheung and Tsang (2005) showed that job-specific social skills training can enhance job retention outcomes in evidence-based supported employment. The disadvantage of job-specific social skills training is that a new programme may have to be tailored for each individual in his or her specific job context. This is not difficult in theory because job-specific social interactions are potentially predictable, but it does take time and resources to develop an effective individualised programme.

\section{Assessing work performance}

Job retention remains a substantial challenge even after the implementation of evidence-based supported employment. A review by McGurk and Mueser (2004) found that despite the superior outcomes of supported employment compared with other forms of vocational rehabilitation, job tenure is often brief, averaging 20 weeks. More systematic methods of assessing work performance appear necessary as a means to support both service users and employers, by aiming to improve knowledge, skills and attitudes in order to improve work performance in a particular job.

The Work Behaviour Inventory (WBI) is a promising tool for this purpose. It was designed as a brief measure of core knowledge skills and attitudes in people with severe mental health problems (Bryson et al 1997) and has been used successfully to improve work performance in employees with schizophrenia. Providing specific feedback using the WBI was found to improve work performance more than conventional support services (Bell et al 2003) and predict future hours worked and future income earned (Bryson et al 1999). These promising results support the use of the WBI as a strategy to improve work performance.

\section{Financial planning and benefits counselling}

Bond (2004) noted that benefits counselling is so beneficial for United States supported employment participants that it is now considered a core principle of evidence-based supported employment. A comprehensive financial plan can be designed and implemented by occupational therapists. Welfare traps, including real and perceived disincentives, can discourage participation in supported employment. The mix of income support and fringe benefit incentives and disincentives varies by country, state, and individual circumstances. 
Access to benefits counselling has been shown to improve earnings for individuals in supported employment. Tremblay et al (2004) showed that those receiving individual benefits counselling earned more compared with those who did not receive this service. Financial planning also shows promise for helping people to make the decision to participate in supported employment. Financial planning may also help with job retention. Once service users are earning wages, they can learn to plan a weekly budget and how to meet their income support notification obligations. This may increase job retention by preventing job loss through service users not attending work because of running out of money for work-related expenses. Occupational therapists can help by developing structured financial planning for all supported employment service users (Auerbach and Jeong 2005).

\section{Managing personal information}

Another promising area for enhancing outcomes in supported employment is through formalising plans to manage sensitive personal information. Previously referred to as disclosure strategies, these can be critical in permitting, or not, any contact with employers on behalf of service users. The authors recommend normalising this issue by setting the need to manage sensitive mental health and forensic information in context with typical strategies adopted by most jobseekers; that is, simply to manage the information to best effect without breaching legal and ethical requirements, as is expected in résumés and job applications.

Some form of health-related information often needs to be shared with employers to access reasonable accommodations in the workplace. However, this information can be provided in work performance terms by discussing work preferences, work strengths and work restrictions due to health conditions. Potentially stigmatising diagnostic labels can be avoided if the work performance implications are the focus of discussion with potential employers (Waghorn and Lewis 2002). Occupational therapists working in mental health can assist by developing individual plans for managing sensitive personal information at point of entry and throughout supported employment assistance.

\section{Work-related self efficacy}

Work-related self-efficacy (Burckhardt 2005, Waghorn et al 2005) is a promising way to identify an individual's assistance needs at the task level in supported employment. Recent studies have shown that work-related self-efficacy is closely associated with employment status (Becker et al 2007, Larson et al 2007, Waghorn et al 2007b). In addition, few employment specialists may be aware of individuals' confidence at a specific task level in supported employment. This is a promising type of enhancement programme for occupational therapists because a simple self-report measure can be used to explore confidence to perform core activities at a specific task level (Waghorn et al 2005). This is important because it can potentially avoid the negative consequences of task failure by assessing in advance whether a particular person needs help with a specific core task or not.

\section{Establishing a work-life balance}

Occupational therapists can help new workers to establish a sustainable work-life balance after employment commences. Balance is about the relationship between a person, his or her occupations and his or her worlds (Finlay 2004). Although there has been very little research on this aspect as a candidate-enhancement programme, it is possible that a lack of occupational balance is associated with poor employment outcomes, increasing ill health and stress among people with severe mental health problems. The new worker may focus overly on work activities while neglecting domestic tasks and responsibilities to family and friends. Occupational therapists are in an ideal position to design and implement this assistance on an individual basis (Finlay 2004).

\section{Preparing for becoming unwell}

Another way in which occupational therapists can assist is by helping participants in supported employment to plan for becoming unwell. A promising method for this purpose is the Wellness Recovery Action Plan (WRAP). This is a structured system for monitoring uncomfortable and distressing symptoms. The planned responses are aimed at reducing, modifying or eliminating those symptoms. The WRAP system consists of a daily maintenance plan, dealing with triggers, dealing with early warning signs, dealing when symptoms occur and the crisis plan (Copeland 2002). It is ideally used in a work context, where specific courses of action involving known individuals can be planned and rehearsed before the person becomes unwell.

\section{Conclusion}

Evidence-based supported employment represents a paradigm shift in mental health rehabilitation. This paradigm shift now challenges occupational therapists working in mental health rehabilitation to revise their theory and practice critically in order to support the implementation of evidence-based practices in supported employment for people with schizophrenia and related psychotic disorders. This is important because if occupational therapists continue to fill traditional roles in mental health teams that do not provide evidence-based practices, they may unwittingly contribute to the ongoing labour force exclusion of people with mental health problems.

A better alternative is for occupational therapists to become familiar with evidence-based practices in supported employment. The enhancement programmes outlined are examples that can be designed and applied by occupational therapists to support evidence-based supported employment. 
By embracing and leading the implementation of evidence-based methods, occupational therapists and other allied health professionals can revitalise their theory and practices in mental health rehabilitation.

Given that work is a central aspect of occupational therapy practice and given the recent government initiatives looking at vocational services for people with severe mental health problems, it seems timely that occupational therapists become proactive in delivering or supporting evidence-based employment services. It is believed that they are well positioned to take this up and ensure that people with severe mental health problems are able to access and maintain competitive employment.

\section{Key findings}

- High quality research has identified evidence-based practices in supported employment, which represents a challenge for occupational therapy. These principles are now at odds with the principles of traditional vocational rehabilitation.

- Occupational therapists can play a role in contributing to evidencebased practices. There are many opportunities for occupational therapists to provide add-on programmes that enhance employment outcomes further for people with mental health problems.

\section{What the paper has added}

This paper examines how occupational therapists can contribute actively to evidence-based practices in vocational rehabilitation for people with mental health problems.

\section{References}

Auerbach ES, Jeong G (2005) Vocational programmeming. In: E Cara, A MacRae, eds. Psychosocial occupational therapy. 2nd ed. Clifton Park, NY: Thomson Delmar Learning, 591-619.

Becker DR, Drake RE (1993) A working life: the Individual Placement and Support (IPS) Program. Concord: New Hampshire-Dartmouth Psychiatric Research Center.

Becker DR, Bond GR, McCarthy D, Thompson D, Xie H, McHugo GJ, Drake RE (2001a) Converting day treatment centers to supported employment programmes in Rhode Island. Psychiatric Services, 52(3), 351-57.

Becker DR, Smith J, Tamzman B, Drake RE, Tremblay T (2001b) Fidelity of supported employment programs and employment outcomes. Psychiatric Services, 52(6), 834-36.

Becker D, Whitley R, Bailey EL, Drake RE (2007) Long-term employment trajectories among participants with severe mental illness in supported employment. Psychiatric Services, 58(7), 922-28.

Bell MD, Lysaker P, Bryson G (2003) A behavioral intervention to improve work performance in schizophrenia: Work Behavior Inventory feedback. Journal of Vocational Rehabilitation, 18(1), 43-50.

Bond G (2004) Supported employment: evidence for an evidence-based practice. Psychiatric Rehabilitation Journal, 27(4), 345-59.

Bond GR, Drake RE (2008) Predictors of competitive employment among patients with schizophrenia. Current Opinion in Psychiatry, 21(4), 362-69.

Bond GR, Becker DR, Drake RE, Rapp, CA, Meisler N, Lehman AF, Bell MD, Blyler CR (2001) Implementing supported employment as an evidence based practice. Psychiatric Services, 52(3), 313-22.
Bond GR, Drake RE, Becker DR (2008) An update on randomized controlled trials of evidence-based supported employment. Psychiatric Rehabilitation Journal, 31(4), 280-90.

Bryson G, Bell MD, Lysaker PH, Zito W (1997) The Work Behavior Inventory: a scale for the assessment of work behavior for people with severe mental illness. Psychiatric Rehabilitation Journal, 20(4), 48-55.

Bryson G, Bell MD, Greig T, Kaplan E (1999) The Work Behavior Inventory: prediction of future work success of people with schizophrenia. Psychiatric Rehabilitation Journal, 23(2), 113-17.

Burckhardt CS (2005) Educating patients: self-management approaches. Disability and Rehabilitation, 27(12), 703-09.

Burns T, Catty J, Becker T, Drake RE, Fiorittie A, Knapp M, Lauber C, Rossler W, Tomov T, vam Busschbach J, White S, Wiersma D (2007) The effectiveness of supported employment for people with severe mental illness: a randomised controlled trial. Lancet, 370, 1146-52.

Cheung LCC, Tsang HWH (2005) Factor structure of essential social skills to be salespersons in retail markets: implications for psychiatric rehabilitation. Journal of Behaviour Therapy and Experimental Psychiatry, 36(4), 265-80.

College of Occupational Therapists (2006) Recovering ordinary lives - the strategy for occupational therapy in mental health services 2007-2017, a vision for the next ten years. London: COT.

Cook JA (2006) Employment barriers for persons with psychiatric disabilities: update of a report for the president's commission. Psychiatric Services, 57(10), 1391-405.

Copeland ME (2002) Wellness recovery action plan. West Dummerston, VT: Peach Press.

Crowther RE, Marshal M, Bond GR, Huxley P (2001) Helping people with severe mental illness to obtain work: systematic review. British Medical Journal, 322, 204-08.

Department of Health (2001) The journey to recovery - the Government's vision for mental health care. London: DH.

Department of Health (2006) Vocational services for people with severe mental health problems. London: $\mathrm{DH}$.

Davis M, Rinaldi M (2004) Using an evidence-based approach to enable people with mental health problems to gain and retain employment, education and voluntary work. British Journal of Occupational Therapy, 67(7), 319-22.

Drake RE, Bond GR (2008) The future of supported employment for people with severe mental illness. Psychiatric Rehabilitation Journal, 31(4), 367-76.

Finlay $L$ (2004) The practice of psychosocial occupational therapy. 3rd ed. Cheltenham: Nelson Thornes.

Gold JM, Goldberg RW, McNary SW, Dixon LB, Lehman AF (2002) Cognitive correlates of job tenure among patients with severe mental illness. American Journal of Psychiatry, 159(8), 1395-403.

Honkonen T, Stengard E, Virtanen M, Salokangas RKR (2007) Employment predictors for discharged schizophrenia patients. Social Psychiatry and Psychiatric Epidemiology, 42(5), 372-80.

Killackey EJ, Jackson HJ, Gleeson J, Hickie IB, McGorry PD (2006) Exciting career opportunity beckons! Early intervention and vocational rehabilitation in first-episode psychosis: employing cautious optimism. Australian and New Zealand Journal of Psychiatry, 40(11-12), 951-62.

King R, Waghorn G, Lloyd C, McLeod P, McMah T, Leong C (2006) Enhancing employment services for people with severe mental illness: the challenge of the Australian service environment. Australian and New Zealand Journal of Psychiatry, 40(5), 471-77. 
Kopelowicz A, Liberman RP, Zarate R (2006) Recent advances in social skills training for schizophrenia. Schizophrenia Bulletin, 32(S1), S12-23.

Larson JE, Barr LK, Kuwabara SA, Boyle MG, Glenn TL (2007) Process and outcome analysis of a supported employment programme for people with psychiatric disabilities. American Journal of Psychiatric Rehabilitation, 10(4), 339-53.

Malouff JM, Thorsteinsson EB, Schute NS (2007) The efficacy of problem solving therapy in reducing mental and physical health problems: a meta-analysis. Clinical Psychology Review, 27(1), 46-57.

McGurk SR, Mueser KT (2004) Cognitive functioning, symptoms, and work in supported employment: a review and heuristic model. Schizophrenia Research, 70(2-3), 147-73.

McGurk SR, Mueser KT, Feldman K, Wolfe R, Pascaris A (2007) Cognitive training for supported employment: 2-3 year outcomes of a randomised control trial. American Journal of Psychiatry, 164(3), 437-41.

Mueser KT, Aalto S, Becker DR, Ogden JS, Wolfe RS, Schiavo D, Wallace CJ, Xie $\mathrm{H}$ (2005) The effectiveness of skills training for improving outcomes in supported employment. Psychiatric Services, 56(10), 1254-60.

Munro I, Edward K (2008) The recovery journey: employment support for people with depression and other mental disorders. Australian e-Journal for the Advancement of Mental Health, 7(2).

Office of the Deputy Prime Minister (2004) Mental health and social exclusion. Wetherby: ODPM Publications.

Penn DL, Roberts DL, Combs D, Sterne A (2007) The development of the social cognition and interaction training programme for schizophrenia spectrum disorders. Psychiatric Services, 58(4), 449-51.

Porteous N, Waghorn G (2007) Implementing evidence-based employment services in New Zealand for young adults with psychosis: progress during the first five years. British Journal of Occupational Therapy, 70(12), 521-26.

Rinaldi M, Perkins R (2007) Comparing employment outcomes for two vocational services: individual placement and support and non-integrated pre-vocational services in the UK. Journal of Vocational Rehabilitation, 27, 21-27.

Rinaldi M, Perkins R, Glynn E, Montibeller T, Clenaghan M, Rutherford J (2008) Individual placement and support; from research to practice. Advances in Psychiatric Treatment, 14(1), 50-60.

Robdale N (2004) Vocational rehabilitation: the Enable Employment Retention Scheme, a new approach. British Journal of Occupational Therapy, 67(10), 457-60.

Rosenheck R, Leslie D, Keefe R, McEvoy J, Swartz M, Perkins D, et al, CATIE Study Investigators Group (2006) Barriers to employment for people with schizophrenia. American Journal of Psychiatry, 163(3), 411-17.

Sainsbury Centre for Mental Health (2007) Mental health and employment. London: Sainsbury Centre for Mental Health.
Shepherd G, Boardman J, Slade M (2008) Making recovery a reality. London: Sainsbury Centre for Mental Health.

Stålberg G, Lichtenstein P, Sandin S, Hultman CM (2008) Video-based assessment of interpersonal problem solving skills in patients with schizophrenia, their siblings and non-psychotic controls. Scandinavian Journal of Psychology, 49(1), 77-82.

Tremblay T, Xie H, Smith J, Drake R (2004) The impact of specialized benefits counseling services on social security administration disability beneficiaries in Vermont. Journal of Rehabilitation, 70(2), 5-11.

Tsang HWH (2001) Applying social skills training in the context of vocational rehabilitation for people with schizophrenia. Journal of Nervous and Mental Disease, 189(2), 90-98.

Tsang H, Pearson V (2000) Reliability and validity of a simple measure for assessing the social skills of people with schizophrenia necessary for seeking and securing a job. Canadian Journal of Occupational Therapy, 67(4), 250-59.

Tsang HWH, Ng BFL, Chiu FPF (2002) Job profiles of people with severe mental illness: implications for rehabilitation. International Journal of Rehabilitation Research, 25(3), 189-96.

Velligan DI, Gonzalez JM (2007) Rehabilitation and recovery in schizophrenia. Psychiatric Clinics of North America, 30(3), 535-48.

Waghorn G, Chant D (2005) Employment restrictions among persons with ICD-10 anxiety disorders: characteristics from a population survey. Journal of Anxiety Disorders, 19(6), 642-57.

Waghorn G, Lewis SJ (2002) Disclosure of psychiatric disabilities in vocational rehabilitation. Australian Journal of Rehabilitation Counselling, 8(2), 67-80.

Waghorn G, Chant D, Whiteford H (2003) The strength of self-reported course of illness in predicting vocational recovery for persons with schizophrenia. Journal of Vocational Rehabilitation, 18(1), 33-41.

Waghorn G, Chant D, White P, Whiteford H (2004) Delineating disability, labour force participation and employment restrictions among persons with schizophrenia. Acta Psychiatrica Scandinavica, 109(4), 279-88.

Waghorn G, Chant D, King R (2005) Work-related self-efficacy among community residents with psychiatric disabilities. Psychiatric Rehabilitation Journal, 29(2), 105-13.

Waghorn G, Collister L, Killackey E, Sherring J (2007a) Challenges to the implementation of evidence-based employment services in Australia. Journal of Vocational Rehabilitation, 27(1), 29-37.

Waghorn G, Chant D, King R (2007b) Work-related subjective experiences, work-related self-efficacy, and career learning among people with psychiatric disabilities. American Journal of Psychiatric Rehabilitation, 10(4), 275-301.

Waghorn G, Chant D, Lloyd C, Harris MG (2009) Labour market conditions, labour force activity and prevalence of psychiatric disorders. Social Psychiatry and Psychiatric Epidemiology, 44, 171-78. 